\title{
Numerical Investigation of Heat Transfer of Nanofluid Flow Past Two Cylinder in Tandem Arrangements
}

\author{
Özge Yetik
}

\begin{abstract}
In this paper, numerical method is developed and simulations of flow and heat transfer of nanofluids is presented. The effect of nanoparticle volume fraction for the enhancement of heat transfer is examined for several sets of values of Reynolds numbers. The study is conducted for pure water and watercopper nanofliud. The study is carried out for Reynolds numbers of 100 and 150 and for volume fraction of nanoparticles of 0 , $0.05,0.10$ and 0.15 . The mean Nusselt numbers for front and rear cylinders are obtained. The obtained results indicated that the increase of nanoparticles volume fraction has a positive effect on the mean Nusselt number.
\end{abstract}

Index Terms-Nanofluid, Tandem arrangement, Flow past cylinder, Fluent.

\section{INTRODUCTION}

Heat transfer from tandem square cylinders has numerous engineering applications such as heat exchanger, heat losses from high-rise buildings, chimneys, pipelines, turbine, piers of a bridge and many other thermal applications. Such fluctuating forced may cause structural vibrations, acoustic noise and resonance and in some cases can trigger structural failure or enhance undesirable flow mixing in the wake [1]. Therefore, it is very important engineering subject.

In tandem circular cylinder with nanofluids have not been studied so far. For this reason, this numerical simulation of steady state and laminar convective heat transfer from two isothermal cylinders of tandem arrangement is carried out by the commercial CFD software -FLUENT. The working fluid is pure water and water based copper nanofluid with different solid fraction values. The analysis is carried out for the Reynolds (Re) numbers of 100 and 150.

The single square cylinder has examined extensively in the studies [2-12]. They examined the change of the $\mathrm{Nu}$ and $\mathrm{St}$ numbers and drag (CD) coefficient for Re numbers ranges from 100 to 160 . All of these studies were simulated in 2D. Mahir [13] studied to investigate the effect of the flow structure in the wake of a square cylinder placed near a plane wall by

Özge Yetik

School of Engineering and Architecture, Mechanical Engineering Department, Eskisehir Osmangazi University

Turkey applying a fully implicit finite-difference method to the NavierStokes equations in two and three-dimensional flow. However, for tandem cases, there are more complex than the single ones because of the existence of two bodies and gap effect.

Chatterjee and Amiroudine [14] carried out to understand the effects of thermal buoyancy and Prandtl (Pr) number on flow characteristics and mixed convention heat transfer over two equal isothermal square cylinders placed in a tandem arrangement within a channel at low Re numbers. The numerical results were presented for the range of conditions as: $1 \leq \operatorname{Re} \leq 30,0.7 \leq \operatorname{Pr} \leq 100$ (the maximum value of Peclet number being 3000) and $0 \leq \mathrm{Ri} \leq 1$ for a fixed blockage parameter $\mathrm{B}=10 \%$. The unsteady numerical simulations were performed with a finite volume code based on the PISO algorithm in a collocated grid system.

Mahir and Altaç [15] investigated numerical simulation of unsteady laminar convective heat transfer from two isothermal cylinders of tandem arrangement. This simulation were carried out by the commercial CFD software -FLUENT. The working fluid was air.

But all of these publications are not use nanofluids. Heat transfer of low Re number or of natural convection flow of nanofluid from a single cylinder has received less attention in the literature[16-20].

Vegad et al [16] was investigated two-dimensional steady state flow for water based copper nanofluid with different solid fraction values around a circular cylinder. They showed that local Nusselt $(\mathrm{Nu})$ number over the cylinder surface had found to increase with increase nanoparticle fraction. Selimefendigil and Öztop [17] numerically studied with mix convection at a backward facing with a rotating cylinder. They reported that $\mathrm{Nu}$ number is a linear increase in the heat transfer rising with increasing Re number and nanoparticle volume fraction. Akçaoğlu et al [18] were numerical studied of natural convection heat transfer of nanofluid in a square enclosure. Results show that Rayleigh (Ra) numbers, solid volume fraction, nanoparticles and partition heights have a significant effect on the flow and heat transfer. Roslan et al [19] were studied with water- $\mathrm{Ag}$, water-Cu, water- $\mathrm{Al}_{2} \mathrm{O}_{3}$ and water- $-\mathrm{TiO}_{2}$ nanofluids. The governing equations were formulated for velocity, pressure and temperature formulation and are modeled in COMSOL, a partial differential equation (PDE) solver based on the Galerkin finite element method (GFEM). 
As a result, the best heat transfer was obtained at a high nanoparticle concentration with a good conductivity value.

\section{PROBLEM DESCRIPTION AND MATHEMATICAL MODEL}

A schematic description of the physical problem and coordinate system considered in this study is shown in Fig. 1. and a typical generated grid is shown in Fig. 2. The circular diameter, height and width of channel are D, $20 \mathrm{D}$ and $32.5 \mathrm{D}$, respectively.

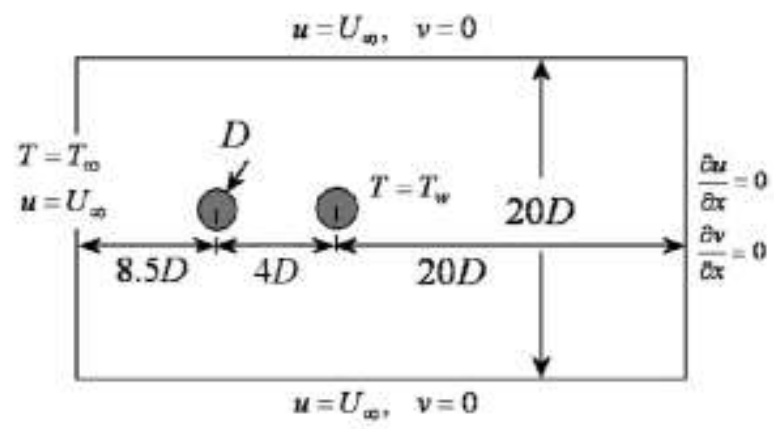

Fig. 1. Schematic diagram of the computational domain.

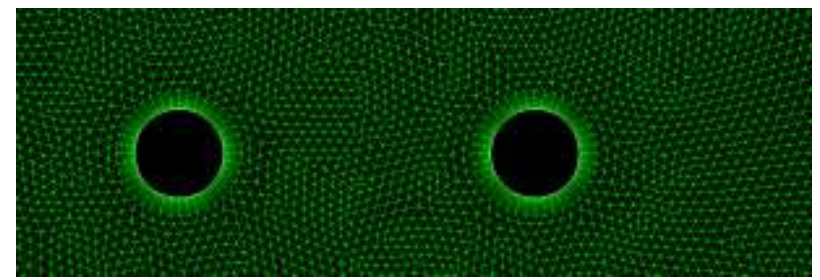

Fig. 2. Grid distribution of the computational domain.

The flow was investigated two dimensional, steady state, laminar and incompressible. The dimensionless governing equations for continuity, two-dimensional Navier-Stokes and the energy equations are given as:

$$
\begin{gathered}
\frac{\partial u}{\partial x}+\frac{\partial v}{\partial y}=0 \\
u \frac{\partial u}{\partial x}+v \frac{\partial u}{\partial y}=-\frac{1}{\rho_{n f}} \frac{\partial p}{\partial x}+v_{n f}\left(\frac{\partial^{2} u}{\partial x^{2}}+\frac{\partial^{2} u}{\partial y^{2}}\right) \\
u \frac{\partial v}{\partial x}+v \frac{\partial v}{\partial y}=-\frac{1}{\rho_{n f}} \frac{\partial p}{\partial y}+v_{n f}\left(\frac{\partial^{2} v}{\partial x^{2}}+\frac{\partial^{2} v}{\partial y^{2}}\right)+g \beta_{n f}\left(T-T_{c}\right)
\end{gathered}
$$

$$
u \frac{\partial T}{\partial x}+v \frac{\partial T}{\partial y}=\alpha_{n f}\left(\frac{\partial^{2} T}{\partial x^{2}}+\frac{\partial^{2} T}{\partial y^{2}}\right)
$$

Where $\mathrm{u}$ and $\mathrm{v}$ are the velocity components in $\mathrm{x}$ and $\mathrm{y}$ coordinates, $\mathrm{T}$ is the temperature of the fluid, $\mathrm{p}$ is the pressure. $\alpha, \rho$ and $v$ denote the thermal diffusivity, density and kinematic viscosity, respectively. The thermo-physical properties of nanofluids are defined using equations. Density of the nanofluid is calculated using particle volume fraction $\phi$ and densities of pure fluid $\rho_{\mathrm{f}}$ and of solid nanoparticles $\rho_{\mathrm{p}}$ as [20]:

$$
\rho_{n f}=(1-\phi) \rho_{f}+\phi \rho_{p}
$$

$\phi$ is the solid volume fraction of nanoparticles. Thermal diffusivity of the nanofluids is

$$
\alpha_{n f}=\frac{k_{n f}}{\left(\rho C_{p}\right)_{n f}}
$$

The thermal expansion coefficient of the nanofluids can be determined by:

$$
(\rho \beta)_{n f}=(1-\phi)(\rho \beta)_{b f}+\phi(\rho \beta)_{p}
$$

The heat capacitance of the nanofluid can be expressed as [21]:

$$
\left(\rho C_{p}\right)_{n f}=(1-\phi)\left(\rho C_{p}\right)_{f}+\phi\left(\rho C_{p}\right)_{p}
$$
[22]:

The ratio of dynamic viscosity of the nanofluids given as

$$
\mu_{n f}=\mu_{f}(1-\phi)^{-2.5}
$$

The ratio of thermal conductivity of the nanofluids approximated by the Maxwell-Garnett formula [23]:

$$
k_{n f}=k_{f}\left[\frac{\left(k_{p}+2 k_{f}\right)-2 \phi\left(k_{f}-k_{p}\right)}{\left(k_{p}+2 k_{f}\right)+\phi\left(k_{f}-k_{p}\right)}\right]
$$


Proc. of The Third Intl. Conf. on Advances in Mechanical and Robotics Engineering - AMRE 2015 Copyright (C) Institute of Research Engineers and Doctors, USA .All rights reserved.

ISBN: 978-1-63248-066-8 doi: 10.15224/ 978-1-63248-066-8-56

Local Nusselt number is defined as [16]:

$$
N u=\left(L \frac{\frac{k_{n f}}{k_{f}}\left(\frac{\partial T}{\partial Y}\right)_{\begin{array}{c}
\text { cylinder } \\
\text { surface }
\end{array}}}{\left(T_{\text {wall }}-T_{\text {basefluid }}\right)}\right)
$$

\section{NUMERICAL METHODOLOGY}

In this study, the finite volume method based on the ANSYS FLUENT package program is used. Problem is twodimensional and steady state. Flow is laminar and slip boundary condition adopted in all surfaces. Second order upwind discrimination method is used momentum and energy equations to reduce errors.

The boundary conditions can be stated as:

- At the inlet, velocity is unidirectional and constant, temperature is uniform. $\left(u=u_{\infty}, v=0, T=300 K\right)$

- At the outlet, gradients of all variables in the $\mathrm{x}$ direction are set to zero. $\left(\frac{\partial u}{\partial x}=0, \frac{\partial v}{\partial x}=0, \frac{\partial T}{\partial x}=0\right)$

- At the cylinder walls, velocity is zero and temperature is uniform. $(u=0, v=0, T=400 K)$

- At the bottom and top walls, velocity is unidirectional and constant, temperature is uniform.

$$
\left(u=u_{\infty}, v=0, T=300 K\right)
$$

In this study, the basic fluid is water and nanoparticles is $\mathrm{Cu}$. Fluid and solid particles thermo physical properties are showed Table 1.

TABLE I. Fluid AND SOLID PARTICLE Thermo PHySiCAL PROPERTIES

\begin{tabular}{|l|l|l|}
\hline \multicolumn{1}{|c|}{ Properties } & \multicolumn{1}{c|}{ Water } & \multicolumn{1}{c|}{$\boldsymbol{C} \boldsymbol{u}$} \\
\hline$\rho\left(\mathrm{kg} / \mathrm{m}^{3}\right)$ & 998.2 & 8978 \\
\hline $\mathrm{C}_{\mathrm{p}}(\mathrm{J} / \mathrm{kgK})$ & 4182 & 381 \\
\hline $\mathrm{k}(\mathrm{W} / \mathrm{mK})$ & 0.6 & 387.6 \\
\hline$\alpha \times 10^{7}\left(\mathrm{~m}^{2} / \mathrm{s}\right)$ & 1.47 & 1163.1 \\
\hline$\beta \times 10^{6}(1 / \mathrm{K})$ & 210 & 16.7 \\
\hline
\end{tabular}

The study is carried out for Reynolds numbers of 100 and 150 and for volume fraction of nanoparticles of $0,0.05,0.10$ and 0.15. Grid testing study is carried out to obtain an independent mesh. Five different grid sizes are controlled and checked. The Nu numbers is given in Table 2 for different grid size at $\operatorname{Re}$ number 100 and $\phi=0$. Grid size of 29565 is decided from this table.
TABLE II. NusSELt Numbers For DifFERENT GRID SizE.

\begin{tabular}{|l|l|l|}
\hline Grid Size & $\begin{array}{c}\text { Averaged Nu Number } \\
\text { (front cylinder) }\end{array}$ & $\begin{array}{c}\text { Averaged Nu Number } \\
\text { (rear cylinder) }\end{array}$ \\
\hline 9341 & 10.35868 & 5.57857 \\
\hline 7785 & 10.27586 & 5.68952 \\
\hline 14577 & 10.13548 & 5.49895 \\
\hline 29565 & 10.13372 & 5.47693 \\
\hline 39748 & 10.12458 & 5.46786 \\
\hline
\end{tabular}

To validate the computational code, the available data in the literature which are mostly studied to air. Figure 3 and figure 4 compares the $\mathrm{Nu}$ number and drag coefficient $\left(\mathrm{C}_{\mathrm{d}}\right)$ in this study and literature at $\operatorname{Re} 100,120,140$ and 160 for single cylinder.

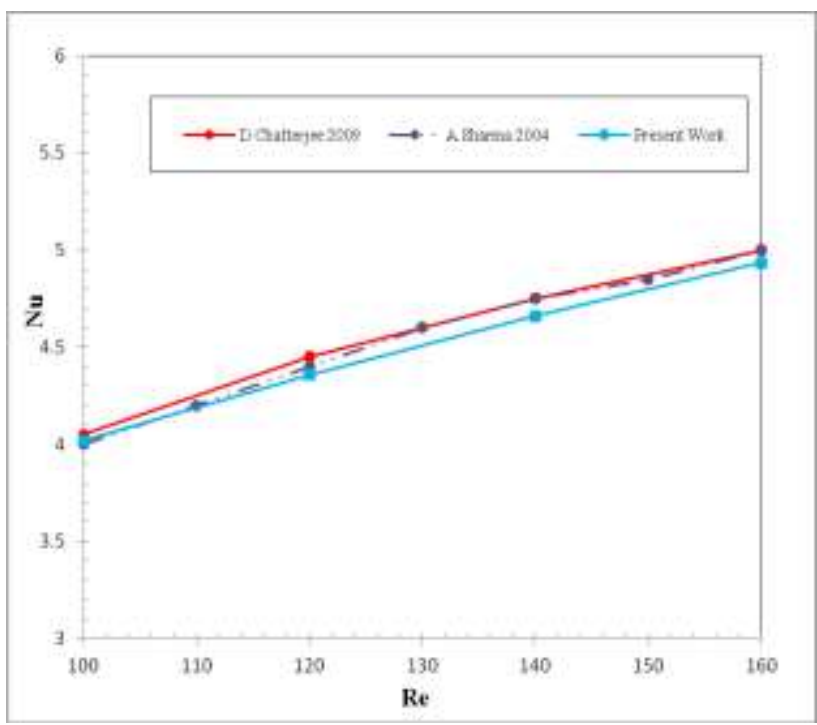

Fig. 3. Comparing the values of Nu number with the data in the literature.

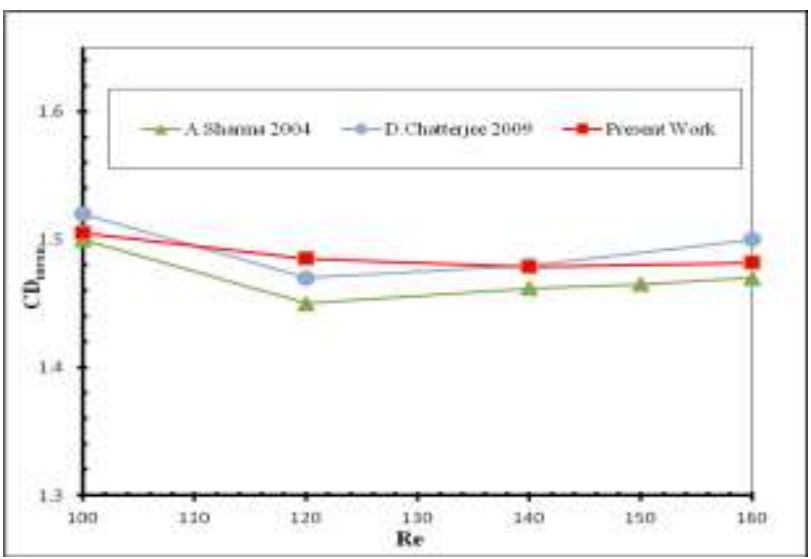

Fig. 4. Comparing the values of $C_{d}$ number with the data in the literature. 
Proc. of The Third Intl. Conf. on Advances in Mechanical and Robotics Engineering - AMRE 2015 Copyright (C) Institute of Research Engineers and Doctors, USA .All rights reserved.

ISBN: 978-1-63248-066-8 doi: 10.15224/ 978-1-63248-066-8-56

\section{RESULT AND DISCUSSION}

Altaç and Mahir [15] said that the L/D values are small, vortex doesn't occur between the cylinders in their study. The vortex street is formed by the boundary layer separated from the upstream cylinder at the downstream region. Because a vortex formation between the two cylinders is not observed for $\mathrm{L} / \mathrm{D}=1.5$, the oscillations increase to form a vortex street for $\mathrm{L} / \mathrm{D}=2.5$ and a vortex occur for $\mathrm{L} / \mathrm{D}=4$. For this reason $\mathrm{L} / \mathrm{D}$ value is considered 4. Figure 5 and Figure 6 show the contours of temperature and velocity for the case of $\phi=0$ at $\operatorname{Re} 150$. Figure 7 shows vectors of velocity for the case of $\phi=0$ at $\operatorname{Re}$ 150 .

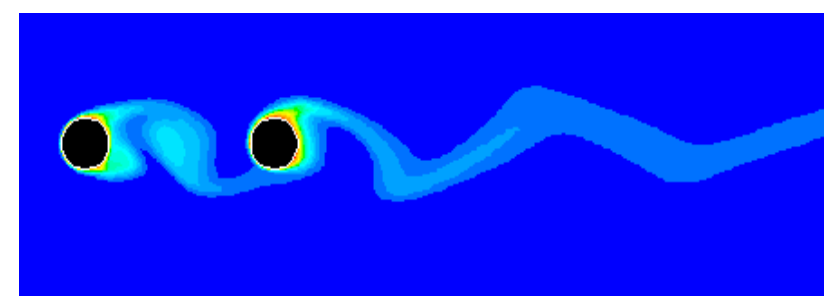

Fig. 5. Contours of temperature for the case of $\phi=0$ at $\mathrm{Re}=150$.

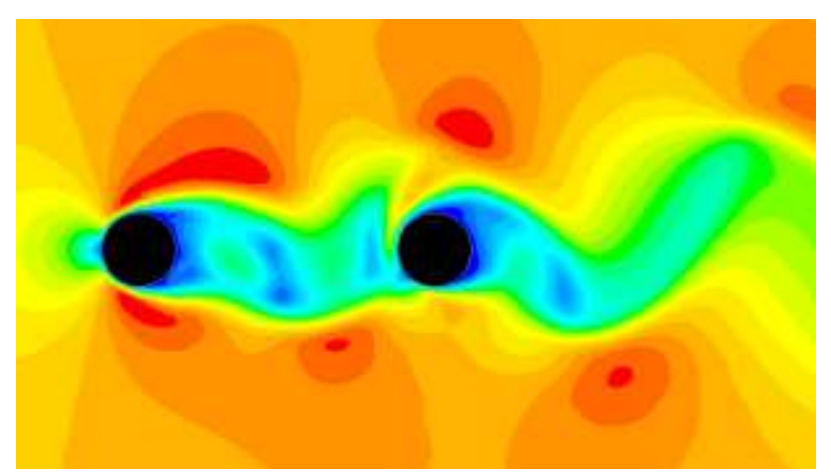

Fig. 6. Contours of velocity for the case of $\phi=0$ at $R e=150$.

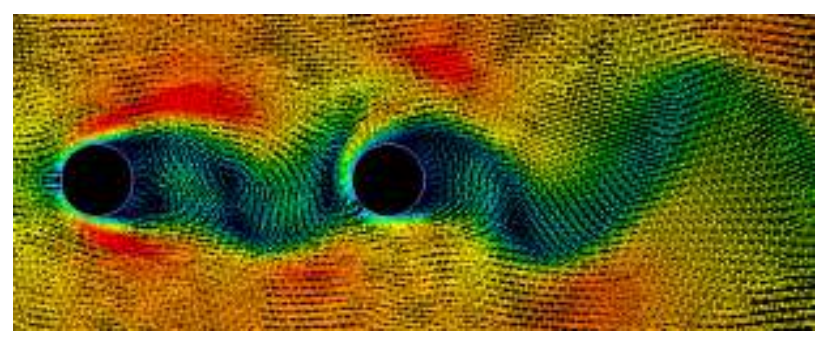

Fig. 7. Vectors of velocity for the case of $\phi=0$ at $\operatorname{Re}=150$.

Figure 8 show that $\mathrm{Nu}$ number variation of nanofluid volume fraction at $\mathrm{Re}=100$ and $\mathrm{Re}=150$. the $\mathrm{Nu}$ number is increased as the particle concentration and $\mathrm{Re}$ number increases.

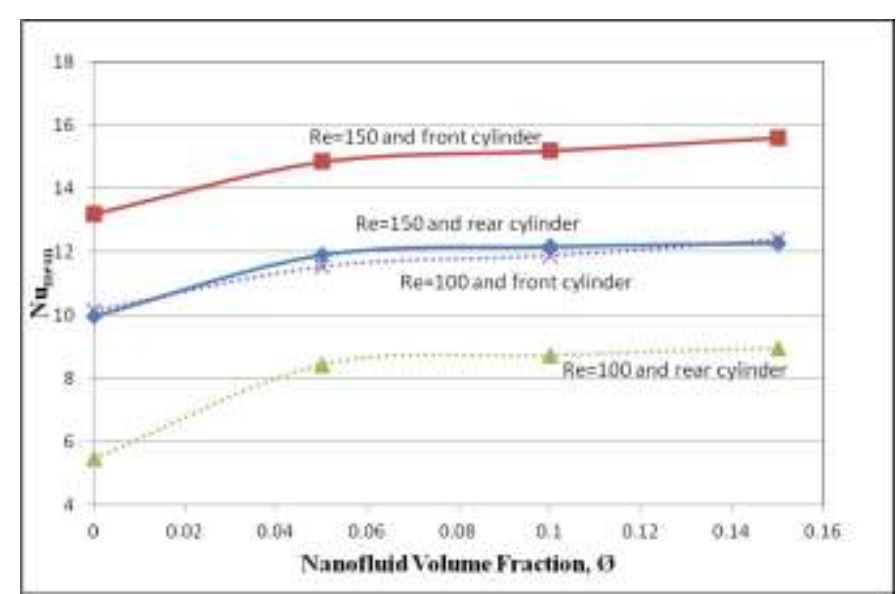

Fig. 8. Nu number variation of nanofluid volume fraction at $\mathrm{Re}=100$ and $\operatorname{Re}=150$.

\section{CONCLUSION}

The paper presents the effect on flow and heat transfer in a tandem circular cylinders with nanofluids. A parametric study is performed for different $\mathrm{Re}$ numbers and solid volume fraction. According to the obtained results, this parameters have important effects on the flow and heat transfer. Due to the water- $\mathrm{Cu}$ nanofluids has the high thermal conductivity, heat transfer has increased between about 18 and 22 percent. Re number is increasing with increasing heat transfer due to the vortex.

\section{REFERENCES}

[1] C. H. K. Williamson, "Evolution of a single wake behind a pair of bluff bodies," Journal of Fluid Mechanics, vol 159, 1985, pp. $1-18$.

[2] R. Franke and W. Rodi, B. Schönung, "Numerical calculation of laminar vortex shedding flow past cylinders, "Journal of Wind Engineering and Industrial Aerodynamics," vol 35, 1990, pp. 237-257.

[3] Y. Shimizu, and Y. Tanida, "Fluid forces acting on cylinders of rectangular cross section," Transc JSME B, vol 44, 1978, pp. 2699-2706.

[4] A. Sharma and V. Eswaran, "Heat and fluid flow across a square cylinder in the two-dimensional laminar flow regime," Numerical Heat Transfer, Part A: Applications: An International Journal of Computation and Methodology, vol 45, 2004, pp. 247-269.

[5] A. Sohankar, C. Norberg and L. Davidson, "Low-Reynolds number flow around a square cylinder at incidence: study of blockage, onset of vortex shedding and outlet boundary condition," International Journal For Numerical in Fluids, vol 26, 1998, pp. 39-56.

[6] A. Sohankar, L. Davidson and C. Norberg, "Numerical simulation of unsteady flow around a square two-dimensional cylinder," Twelfth Australasian Fluid Mechanics Conference, The University of Sydney, Australia, 1995.

[7] Chatterjee, D., Biswas, G. and Amiroudine, S., 2009, "Numerical investigation of forced convection heat transfer in unsteady flow past a row of square cylinders," International Journal of Heat and Fluid Flow, 30, 1114-1128. 
[8] A.K. Sahu, R.P. Chhabra and V. Eswaran, "Effects of Reynolds and Prandtl number on heat transfer from a square cylinder in the unsteady flow regime," International Journal of Heat and Mass Transfer, vol. 52, 2009, pp. 839-850.

[9] A.K. Sahu, R.P. Chhabra and V. Eswaran, "Two-dimensional unsteady laminar flow of a power law fluid across a square cylinder," Journal of Non-Newtonian Fluid Mechanics, vol. 160, 2009, pp. 157-167.

[10] J. Robichaux, S. Balachandar and S.P. Vanka, "Threedimensional Floquet instability of the wake of square cylinder," Physics of Fluids vol. 11, 1999, pp. 560-578.

[11] A. Sohankar, C. Norberg and L. Davidson, "Numerical simulation of unsteady low-Reynolds number flow around rectangular cylinders at incidence," Journal of Wind Engineering and Industrial Aerodynamics, vol. 69, 1997, pp. 189-201.

[12] S.C. Luo, Y.T. Chew and Y.T. Ng, "Hysteresis phenomenon in the galloping ascillation of a square cylinder," Journal of Fluids and Structures, vol. 18, 2003, pp. 103-118.

[13] N. Mahir, "Tree-dimensional flow around q square cylinder near a wall," Ocean Engineering, vol. 36, 2009, pp. 357-367.

[14] D. Chatterjee and S. Amiroudine, "Two-dimensional mixed convection heat transfer from confined tandem square cylinders in cross-flow at low Reynolds numbers," International Commications in Heat and Mass Transfer, vol. 37, 2010, pp. 7 16.

[15] N. Mahir and Z. Altaç, "Numerical investigated of convective heat transfer in unsteady flow past two cylinders in tandem arranegments," International Journal of Heat and Fluid Flow, vol. 29, 2008, pp. 1309-1318.
[16] M. Vegad, S. Satadia, P. Pradip, P. Chirag and P. Bhargav, "Heat transfer characteristic of flow Reynolds number flow of nanofluid around a heated circular cylinder," Procedia Technology, vol. 14, 2014, pp. 348-356.

[17] F. Selimefendigil and H.F. Öztop, "Numerical investigation and reduced order model of mixed convection at a backward facing step with a rotating cylinder subjected to nanofluid," Computers and Fluids, vol. 109, 2015, pp. 27-37.

[18] E. Akçaoğlu, M. Arıcı and E.B. Öğüt, "Bölmeli bir kare kapalı ortam içindeki nanoakışkanın doğal konveksiyonla 1S1 transferşnşn sayısal olarak incelenmesi," Erciyes University Journal of Institute of Science and Technology, vol. 28, 2012, pp. 359-366.

[19] R. Roslan, H. Saleh and I. Hashim, "Effect of rotating cylinder on heat transfer in a square enclosure filled with nanofluids," International Journal of Heat and Mass Transfer, vol. 55, 2012, pp. 7247-7256.

[20] J. Ravnik and L. Skerget, "A numerical study of nanfluid natural convection in a cubic enclosure with a circular and an ellipsoidal cylinder," International Journal of Heat and Mass Transfer, vol. 89, 2015, pp. 596-605.

[21] K. Khanafer, K. Vafai and M. Lightstone, "Buoyancy-driven heat transfer enhancement in a two-dimensional enclosure utilizing nanofluids," Int. J. Heat Transfer, vol. 46, 2003, pp. 3639-3653.

[22] H.C. Brinkman, "The viscosity of concentrated suspensions and solutions," J. Chem. Phys. vol. 20, 1952, pp. 571-581.

[23] J.C. Maxwell, "A Treatise on Electricity and Magnetism, second ed.," Clarendon Press, Oxford, UK, 1881. 